\title{
Assessment of Anticardiolipin antibodies, Circulating Lupus anticoagulant, Protein C, Protein S, Antithrombin III \&Activated Protein C Resistance and Their Relation to Thomboembolic and Other Clinical Manifestations in Behcet's Disease
}

\author{
Seham M. S.EL- Nakeeb*, Ahmed M.Ragheb**, H.S.EI -Baz**, \\ Abdel ShafyA.H***, A.M.Salama*****, and Zeinab A.Zakzouk***** \\ Biochemistry*, Chest***** Dept. Faculty of Medicine for Girls. \\ Clinical Pathology**, Rheumatology and Rehabilitation***, Vascular Surgery**** Dept. \\ Faculty of Medicine AL-Azhar University
}

\begin{abstract}
Background: Venous and arterial thrombosis occurs in patients with Behcet's disease and is associated with significant morbidity and mortality. Studies on a possible association between the occurrence of thrombosis and thrombophilia in patients with this disease have been controversial. The objective of this study was to assess the frequency and clinical relevance of anticardiolipin antibodies (aCL) \& other thrombophilic factors and their relationship to thromboembolic \& clinical manifestations in Behcet's disease(BD).

Materials and methods: $\operatorname{IgG}, \operatorname{IgM}$ and $\operatorname{IgA}$ anticardiolipin antibodies (aCL) isotypes, presence of circulating lupus anticoagulant(LAC), protein $\mathrm{C}$, protein $\mathrm{S}$, antithrombin III \& activated protein $\mathrm{C}$ resistance were investigated in 25 patients with $\mathrm{BD}$ and 25 patients with various rheumatic diseases not known to be associated with venous or arterial thromboembolic phenomena served as controls. Twelve of the patients with BD (48\%) had either deep vein thrombosis (8 patients), arterial thromboembolic phenomena (4 patients), or both (2 patients).

Results: The IgA aCL elevated in14 (56\%) patients with BD compared with one (4\%) patient in the control group $(P<0.01)$. IgG aCL levels were elevated in $13(52 \%)$ patients with Behcet's disease (BD) compared with one $(4 \%)$ patient in the control group $(P<0.01)$. Also patients with BD do not have decreased protein $\mathrm{S}$, or antithrombin III activity, activated protein $\mathrm{C}$ resistance, circulating lupus anticoagulant (LAC), or elevated LgM aCL. No significant differences were found between any variable in both groups. No association between elevated IgMaCL levels and venous or arterial thrombosis and no statistical correlation was found between any factor and clinical manifestations of the disease.

Conclusion: A significant number of patients have elevated levels of IgA\& IgG aCL but they are not associated with venous or arterial thrombosis. These results do not suggest a primary role for aCL in $\mathrm{BD}$ and do not support the role of coagulation abnormalities in the pathogenesis of thromboembolic complications of Behcet's disease but suggest vascular inflammation as the main pathogenetic event in the vascular lesions in Behcet's disease.
\end{abstract}

KEY WORDS: Procoagulant factors, Anticardiolipin antibodies, Thromboembolic manifestations, Behcet's disease.

\section{Introduction}

Behcet's disease (BD) is a chronic multisystem inflammatory disorder that can involve the skin, eyes, central nervous system, arteries, veins, lungs, and gastrointestinal tract. The common manifestations are recurrent oral and genital ulcers and ocular inflammation. Venous or arterial thrombosis occurs in 7-38\% of patients (Sakane et al.,1999).Venous thrombosis is more common than arterial thrombosis, with relative frequencies of $90 \%$ and $10 \%$, respectively. Deep or superficial venous thrombosis in the lower extremities is the common sites of thrombosis (Gul et al., 
1996; Kuzu et al., 1994). Vasculitis underlies the thrombotic tendency in Behcet's disease, but it is not clear why some patients present with thrombosis and others do not. Decreased levels of tissue plasminogen activator and thrombomodulin, and increased levels of plasminogen activator inhibitor-1, von Willebrand factor, thrombin-antithrombin complex, prothrombin fragment $1+2$, and lipoprotein (a) (Lp (a)) have all been described in patients with Behcet's disease and related to the thrombotic tendency (Leiba et al., 2001; Ozatli et al., 2002). The possible role of acquired and inherited thrombophilias has also been evaluated. However, there are conflicting data in patients with and without thrombosis over the prevalence of factor $\mathrm{V}$ Leiden, methylenetetrahydrofolate reductase (MTHFR) C677T homozygosity, homocysteine level, prothrombin G20210A polymorphism, and levels of factor VIIa, factor VIII, and factor XII (Kiraz et al., 2002). A recently described thrombophilic index-decreased plasma glucosylceramide concentration-has not been examined yet in patients with Behcet's disease (Deguchi et al., 2001).

The cause and pathogenesis of $\mathrm{BD}$ are unclear, but various immunological abnormalities associated with both humoral and cellular immune systems have been reported (Direskeneli et al., 1999). Anticardiolipin antibodies (aCL) are antibodies against the phosphodiester group of negatively charged phospholipids. Recurrent thrombosis, fetal loss and thrombocytopenia have been reported to be associated with the presence of aCL, especially in autoimmune diseases such as systemic lupus erythematosus (SLE) (Harris et al.,1986).BD is also characterized by recurrent vascular thrombosis and vasculitis. Although some previous studies suggest an increased frequency of aCL in $\mathrm{BD}$, the low numbers of patients in most of these studies, especially patients with thrombotic complications, make it difficult to draw definite conclusions (Pereira et al.,1989 ; Kang et al., 1998 \& Ozdemir et al.,1997; Mader et al.,1999). Ethnic and geographical differences in $\mathrm{BD}$ related to the clinical manifestations, such as gastrointestinal involvement, positive pathergy reaction and HLA-B51, are well known (Yurdakul et al., 1996 ; Yazc et al., 1984), and aCL levels might be influenced by these factors. Therefore, this study aimed to assess the frequency and clinical relevance of $\operatorname{IgG}, \operatorname{IgM}$ and $\operatorname{IgA}$ anticardiolipin antibodies (aCL) isotypes, presence of circulating lupus anticoagulant (LAC), protein $\mathrm{C}$, protein $\mathrm{S}$, antithrombin III \& activated protein $\mathrm{C}$ resistance and their relationship to thromboembolic \& clinical manifestations in Behcet's disease(BD).

\section{Materials and methods}

\section{Patients}

Patients with Behcet's disease (BD) $(n=25 ; 12$ females, 13males; mean age $36.8 \pm 5.7 \mathrm{yr}$ ) and patients with various rheumatic diseases $(n=25 ; 17$ females, 8 male; mean age $39.0 \pm 4.2 \mathrm{yr}$ ) attending the rheumatology outpatient clinical at the ElHussein University Hospital. All Behcet's disease patients fulfilled the Criteria for diagnosis of BD. Twelve of the patients with BD (48\%) had either deep vein thrombosis, confirmed by Doppler ultrasound, (8 patients), arterial thromboembolic phenomena (4 patients), or both (2 patients).Three patients had pulmonary embolism (supported by lung scan ventilation/ perfusion mismatched) and one patient had cerebral vascular accident.

In the control group there were 25 patients with various rheumatic diseases not known to be associated with venous or arterial thromboembolic phenomena (10 with osteoarthritis, 9 with rheumatoid arthritis, 3 with psoriatic arthritis and 3 with fibromyalgia). Careful history and clinical examination were done to all patients.

\section{Biochemical analysis}

Venous blood samples $(10 \mathrm{ml})$ were collected after an overnight fasting in tubes containing EDTA and were immediately centrifuged at $1500 \mathrm{rpm}$ for $15 \mathrm{~min}$ at $4^{\circ} \mathrm{C}$. Plasma samples were protected from light $\&$ frozen at $-80^{\circ} \mathrm{C}$ and stored until analysis. Plasma IgG, IgM and IgA anticardiolipin antibodies (aCL) were determined accor- 
ding to the method of Gharavi et al . (1987) using the standard ELISA method (Reaads, westminister). Circulating lupus anticoagulant (LAC) test was performed by measurement of the activated partial thromboplastin time (APTT) without and with mixing of normal plasma pool, dilute Russell's viper venom time (Bioclot LA), and Koalin clotting time (Gradipore Ltd).A positive test was defined by abnormal results by at least 2 techniques and confirmed by platelet neutralizing procedures. Protein S activity was measured by an automated functional clotting, protein $\mathrm{S}$ assay based on prolongation time (IL Spa). Protein C activity and antithrombin III activity were measured by chromogenic assay (IL Spa). Activated protein C resistance test is a modified activated partial thromboplastin time (APTT) in which the anticoagulant response to standerized addition of activated protein $\mathrm{C}$ is measured by clotting time of APTT (Chromogenix) the ratio of the tests with and without addition of activated protein $\mathrm{C}$ is calculated and a low ratio $(<25)$ is suggestion of activated protein $\mathrm{C}$ resistance.

\section{Statistical analysis}

Statistical analysis was performed using fisher's exact test to detect correlation of variable studies between patients and controls and to detect correlation between variables and clinical manifestations.

Results
According to (Table 1), the clinical manifestations of 25 patients with Behcet's disease involved mouth ulcers in 23 patients $(92 \%)$, genital ulcers in 21 patients $(84 \%)$, eye lesions in 16 patients (64\%), skin lesions in 14 patients (56\%), positive pathergy test in 10 patients (40\%), arthritis in 15 patients (60\%), deep vein thrombosis in 8 patients (32\%), other thromboembolic phenomena in 4 patients (16\%) and neurological manifestations in 3 patients (12\%).

According to (Table 2) and (Fig. $1 \& 2)$, the results showed statistically higher prevalence of $\operatorname{IgA}$ aCL isotype in 14 patients $(56 \%) \& \operatorname{IgG}$ aCL isotype in 13 patients with Bechcet's disease (52\%) then prevalence of IgA, IgG aCL in only one patient from control group (4\%) with $\mathrm{P}<0.01$. However, no correlation was found between elevated level of aCL and thromboembolic complications or other clinical manifestation of the disease. Other procoagulant factors such as IgM aCL isotype, LAC, protein $\mathrm{C}$ activity and antithrombin III activity showed no significant elevation of their levels, no difference between levels in both patients with Behcet's disease and control group and no correlation between any one of them and clinical disease manifestations. Among 5 patients with low activated protein $\mathrm{C}$ resistance ratio, one patient had elevated level of IgG aCL.

Table (1): Clinical characteristics in patients with Behcet's disease. 


\begin{tabular}{|l|c|}
\hline \multicolumn{1}{|c|}{ Clinical manifestations } & Number of patients (\%) \\
\hline Mouth ulcers & $23(92 \%)$ \\
\hline Genital ulcers & $21(84 \%)$ \\
\hline Eye involvement: & $16(64 \%)$ \\
-Anterior uveitis & $10(40 \%)$ \\
-Posterior uveitis & $3(12 \%)$ \\
-Retinal vasculitis & $3(12 \%)$ \\
& \\
\hline Skin involvement: & $14(56 \%)$ \\
-Erythema nodosum & $8(32 \%)$ \\
-Pseudofolliculitis & $4(16 \%)$ \\
-Papulopustulatic lesions & $2(8 \%)$ \\
\hline Positive pathergy test & $10(40 \%)$ \\
\hline Arthritis & $15(60 \%)$ \\
\hline Vascular lesion: & $12(48 \%)$ \\
-Deep vein thrombosis & $8(32 \%)$ \\
-Pulmonary embolism & $3(12 \%)$ \\
-Cerebral vascular accident & $1(4 \%)$ \\
\hline Neurological manifestations & $3(12 \%)$ \\
\hline
\end{tabular}

Table (2): Thrombophilic factors in patients with Behcet's disease and controls.

\begin{tabular}{|l|c|c|}
\hline \multicolumn{1}{|c|}{ Thrombophilic factors } & BD & Controls \\
\hline -Elevated IgA aCL & $14(56 \%)$ & $1(4 \%)$ \\
\hline -Elevated IgG aCL & $13(52 \%)$ & $1(4 \%)$ \\
\hline - Elevated IgM aCL & $3(12 \%)$ & $1(4 \%)$ \\
\hline - Positive lupus anticoagulant(LAC) & $1(4 \%)$ & $0(0 \%)$ \\
\hline -low Protein C activity & $0(0 \%)$ & $0(0 \%)$ \\
\hline -low Protein S activity & $1(4 \%)$ & $0(0 \%)$ \\
\hline -low antithrombin III activity & $1(4 \%)$ & $1(4 \%)$ \\
\hline -low activated protein C resistance & $5(20 \%)$ & $1(4 \%)$ \\
\hline
\end{tabular}

Fig. (1): IgG, IgM and IgA anticardiolipin antibodies in patients with Behcet's disease and controls.

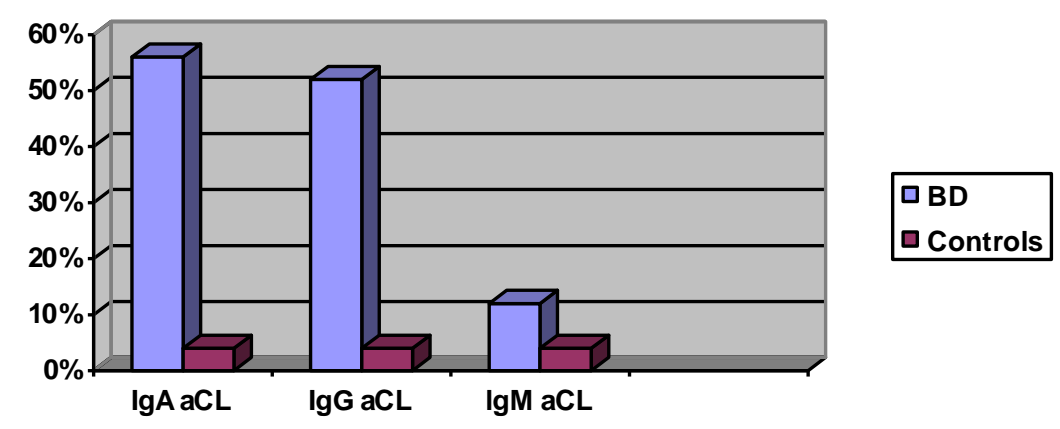

Fig. (2): Thrombophilic factors in patients with Behcet's disease and controls. 


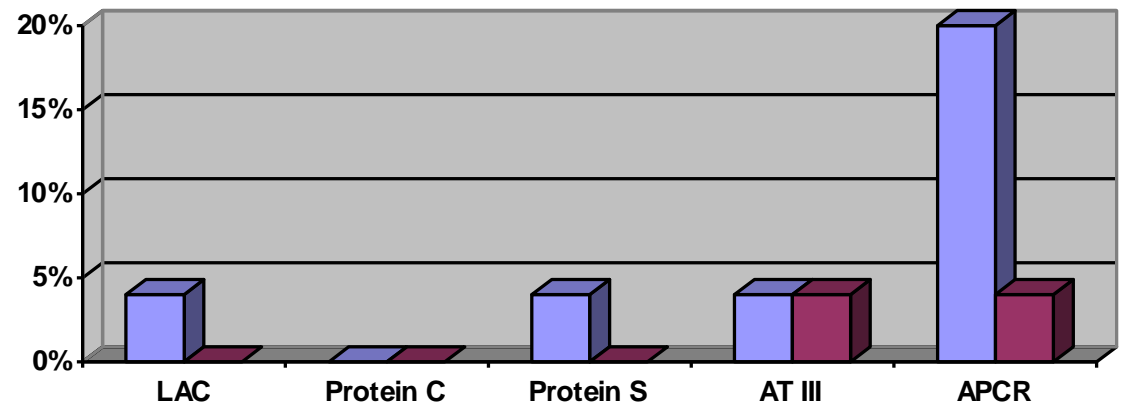

\section{Discussion}

Behcet's disease (BD) is a chronic, inflammatory vasculitis characterized by mucocutaneous, ocular, vascular, arthritic and neurological involvement (Yazc et al ., 1999). Pulmonary aneurysms represent the major complication of pulmonary Behcet's disease and have a poor prognosis, being associated with massive haemoptysis. In situ pulmonary artery thrombus can lead to pulmonary infarction. Superior vena cava thrombosis progresses slowly, allowing the development of a prominent collateral circulation. Vascular inflammation can spread to the mediastinum, the pleura and the lungs with diffuse pulmonary haemorrhages, bronchiolitis and organising pneumonia (Hamzaoui and Hamzaoui, 2005 ). Venous thrombosis affects one in 1000 individuals per year causing significant morbidity and mortality (Rosendaal,1997). Vascular lesions can involve both arterial and venous systems which are often the major cause complicating the disease course of Behcet's disease. Vascular lesions can be the presenting sign of Behcet's disease preceding classical symptoms (Sarica-Kucukoglu et al., 2006). Our results showed that the prevalence of vascular involvement in $\mathrm{BD}$ was $48 \%$.The venous lesions represented $32 \%$ and were mainly venous occlusions, the arterial lesions represented $16 \%$ and were either arterial aneurysms and/ or arterial occlusions.

The pathogenesis of arterial and venous thrombosis in Behcet's disease is not completely understood. It is generally accepted that vasculitis, a hallmark of Behcet's disease, partially explains the initiation of thrombosis in small as well as large blood vessels (Sarica-Kucukoglu, 1997). Vasculitic lesions are characterized by perivascular lymphocyte and mononuclear cell infiltration, endothelial edema, degeneration of the elastic lamina interna, fibrinoid necrosis, and deposition of immune complexes within the vascular wall. The inflammation usually affects all layers of the vessel wall with very adherent thrombi in the lumen. For this reason, although large segments of the vessel wall are affected, pulmonary emboli are quite rare in BD. Pulmonary disease consists mainly of pulmonary artery thrombi, infarcts, aneurysms, and arteriobronchial fistula. Endothelial cell injury due to vasculitis seems to be a key event in the prethrombotic state of BD (Leiba et al., 2001). Vascular endothelial growth factor (VEGF) is a stimulant of angiogenesis secondary to ischemia while monocyte chemoattractant protein 1 (MCP-1) is induced by shear stresses leading to vascular collateral development. MCP-1 has been also shown to contribute to the recanalization of venous thrombi. Tumour necrosis factor-alpha (TNF-alpha) is known to play a major role in the pathogenesis of BD. Furthermore, up-regulation of secreted MCP-1 and VEGF was observed following stimulation with TNF-alpha. Increased levels of VEGF and MCP-1 detected in BD thrombosis suggest the possible role of those angiogenic cytokines in the 
pathogenesis. Although not specific for $\mathrm{BD}$, detection of VEGF or MCP-1 levels seems to serve as an assay for differentiation of BD patients with acute thrombosis from chronic (Bozoglu et al., 2005).

In the literature, the frequency of aCL in BD ranges between 0 and 50\%. Hull et al (1984) first reported 19\% positivity for aCL and found an association between increased IgM and $\operatorname{IgG}$ aCL levels and retinal vasculitis. A similar relationship with uveitis was later suggested in other studies. Pereira et al. (1989) observed IgG aCL positivity in three of 10 patients $(30 \%)$ with ocular disease and a lower frequency in patients taking corticosteroids (27.3 vs 55.6\%). Musabak et al. (2005) also found that anticardiolipin antibody $-\operatorname{IgG}$ and $\operatorname{IgM}$ levels were higher in patients with active BD than healthy controls but not higher than patients with inactive BD. Zouboulis et al. (1993) reported high IgM aCL titres in patients with cutaneous vasculitis and erythema nodosum. Apart from these studies, no correlation was observed with any specific manifestation of $\mathrm{BD}$ and $\mathrm{aCL}$ antibodies, especially with thrombotic events, as might be expected. In Tokay et al . (2001) study, which includes the largest number of patients reported, they found that the frequency of $\mathrm{IgG}$ and IgM aCL to be $2.4 \%$ in BD, $50 \%$ in SLE and 5.6\% in healthy controls. While the frequencies in the SLE and control groups were similar to those in other studies, they did not find increased IgM and IgG aCL in BD. They were also unable to show any significant association between aCL and vascular or ocular involvement, disease duration, pathergy positivity, a high erythrocyte sedimentation rate or immunosuppressive treatment. In the current study the IgA aCL elevated in $14(56 \%)$ in patients with BD compared with one (4\%) patient in the control group $(P<0.01)$. IgG aCL levels were elevated in $13(52 \%)$ in patients with Behcet's disease compared with one $(4 \%)$ patient in the control group $(P<0.01)$. Also patients with BD do not have decreased protein S, or antithrombin III activity, activated protein $\mathrm{C}$ resistance, circulating lupus anticoagulant (LAC), or elevated IgM aCL. No significant differences were found between any variable in both groups. No association between elevated IgM aCL levels and venous or arterial thrombosis and no statistical correlation was found between any factor and clinical manifestations of the disease. These results are in agreement with most previous reports, especially study of Mader et al. (1999) who suggest an increased frequency of $\mathrm{IgG}$ aCL in BD and Tokay et al(2001) who found a slight increase of $\operatorname{IgA}$ aCL in $\mathrm{BD}$ patients and also no correlation was found between serum IgA levels and IgA aCL. In our study the prevalence of elevated anticardiolipin antibodies (aCL) was elevated in about $50 \%$ of BD patients with vascular thrombosis. The aCL neither correlate with clinical manifestations of $\mathrm{BD}$, nor correlate with other coagulation abnormalities. Thrombophilia does not seem to play a major role in the tendency to thrombosis in Behcet's disease. However, dyslipidaemia, predominantly hypertrigl-yceridaemia, might be a risk factor (Leiba et al, 2004).

In our patients, although statistical significance was not achieved, 5 patients had an abnormal activated protein $\mathrm{C}$ resistance test. It seems that $\mathrm{aCL}$ might interfere with the activation of protein $\mathrm{C}$, reducing the circulating levels of activated protein $\mathrm{C}$ and increasing risk of thrombosis. Activated protein $\mathrm{C}$ inhibits the procoagulant function of activated factor $\mathrm{V}$ (FVa), through proteolytic cleavages at Arg306, Arg506 and Arg679. The cleavage at $\operatorname{Arg} 506$ is kinetically favored, but protected by factor Xa (FXa). Protein S has been suggested to annihilate the inhibitory effect of FXa, a proposal that has been challenged. Protein $S$ counteracted the inhibition by FXa of the Arg506 cleavage, whereas protein $\mathrm{S}$ and $\mathrm{FXa}$ yielded additive stimulatory effect of the cleavage at Arg306. This suggests that FXa and protein $\mathrm{S}$ interact with distinct sites on $\mathrm{FVa}$, which is consitent with the observed lack of inhibitory effect on FXa binding to FVa by protein $\mathrm{S}$. The apparent annihilation of the FXa protection of the Arg506 cleavage by protein $S$ is due to enhanced rate of Arg506 cleavage of FVa not bound to FXa resulting in depletion of free FVa and dissociation of 
FXa-FVa complexes (Norstrom et al., 2006).

\section{Conclusion}

A significant number of patients have elevated levels of IgA\& IgG aCL but they are not associated with venous or arterial thrombosis. These results do not suggest a primary role for aCL in $\mathrm{BD}$ and do not support the role of coagulation abnormalities in the pathogenesis of thromboembolic complications of Behcet's disease, but suggest vascular inflammation as the main pathogenetic event in the vascular lesions in Behcet's disease.

\section{References}

1. Bozoglu E. Dinc A. Erdem H.0 Pay S. Simsek I. Kocar IH. (2005): Vascular endothelial growth factor and monocyte chemoattractant protein-1 in Behcet's patients with venous thrombosis.Clin Exp Rheumatol., 23(4 Suppl 38):S42-8.

2. Deguchi H , Fernandez JA, Pabinger I, Heit JA, Griffin JH. (2001) Plasma glucosylceramide deficiency as potential risk factor for venous thrombosis and modulator of anticoagulant protein $\mathrm{C}$ pathway., Blood, 97:1907-14.

3. Direskeneli H, Eksioglu-Demiralp E, Akoglu T.(1999): Etiopathogenesis of Behçet's syndrome: Recent developments and current controversies.Marmara Med J, 12:101-6.

4. Gharavi AE, Harris EN, Asherson RA, Hughes GRV.(1987) Anticardiolipin antibodies: isotype distribution and phospholipid specificity. Ann Rheum Dis., 1987;46:1-6.

5. Gul A, Ozbek U, Ozturk C, Inanc M, Konice M, Ozcelik T.(1996): Coagulation factor $\mathrm{V}$ gene mutation increases the risk of venous thrombosis in Behcet's disease. $\mathrm{Br} \mathbf{J}$ Rheumatol., 35:1178-80.

6. Hamzaoui A, Hamzaoui K. (2005): Pulmonary complications of Behcet's disease and Takayasu's arteritis. Rev Mal Respir., 22(6 Pt 1):999-1019.

7. Harris EN, Phil M, Chan JKH et al. (1986): Thrombosis, recurrent fetal loss and thrombocytopenia. Arch Intern Med., 146:2153-6.

8. Hull RG, Harris EN, Gharavi AE et al.(1984): Anticardiolipin antibodies: occurrence in Behçet's syndrome. Ann Rheum Dis., 43:746-8.

9. Kang HJ, Lee YW, Han SH, Cho HC, Lee KM.(1998): Anti-cardiolipin and antiB2-glycoprotein I antibodies in Behçet's disease. J Korean Med Sci., 13:400-4.

10. Kiraz S, Ertenli I, Ozturk MA, Haznedaroglu IC, Celik I, Calguneri M. (2002): Pathological haemostasis and prothrombotic state in Behcet's disease. Thromb Res., 2002; 105:125-33.

11. Kuzu MA, Ozaslan C, Koksoy C, Gurler A, Tuzuner A. (1994): Vascular involvement in Behcet's disease: 8 year audit. World J Surg., 18:948-54.

12. Leiba M , Sidi Y, Gur H, Leiba A, Ehernfeld M. (2001): Behcet's disease and thrombophilia.Ann Rheum Dis.,60:1081-5.

13. Leiba M, Seligsohn U, Sidi Y, Harats D, et al.(2004): Thrombophilic factors are not the leading cause of thrombosis in Behçet's disease. Annals of the Rheumatic Diseases., 63:14451449.

14. Mader R, Ziv M, Adawi M, Mader R, Lavi I. (1999): Thrombophilic factors and their relation to thromboembolic and other clinical manifestations in Behçet's disease. J Rheumatol., 26:2404-8.

15. Musabak U, Baylan O, Cetin T,et al. (2005): Lipid profile and anticardiolipin antibodies in Behcet's disease.Arch Med Res. 36(4):387-92.

16. Norstrom EA, Tran S, Steen M, Dahlbäck B.(2006): Effects of factor $\mathrm{Xa}$ and protein $\mathrm{S}$ on the individual activated protein $\mathrm{C}$ mediated cleavages of coagulation factor Va. J Biol Chem., 25: 1074.

17. Ozatli D , Sayinalp N, Buyukasik Y, Karakus S, Haznedaroglu IC, Kirazli S, et al. (2002): Unchanged global fibrinolytic capacity despite increased factor VIIa activity in Behcet's disease: evidence of a prethrombotic state. Rheumatol Int., 21: $137-40$.

18. Ozdemir Y, Onder F, Yarangumeli A, Kucukkuyumcu C, Kural G.(1997): Anticardiolipin antibodies and retinal vascular complications in Behçet's disease. Ophthalmic Surg Lasers., 28:653-6.

19. Pereira RM, Goncalves CR, Bueno C, Meirelles $E$ de $S$, Cossermelli $W$, de Oliveira RM. (1989) : Anticardiolipin antibodies in Behçet's syndrome: a 
predictor of a more severe disease. Clin Rheumatol., 8:289-91.

20. Rosendaal F.(1997): Risk factors for venous thrombosis: prevalence, risk and interaction. Sem Haematol., 34:171-187.

21. Sakane T, Takeno M, Suzuki N, Inaba G.(1999): Behcet's disease. N Engl J Med., 341:1284-91.

22. Sarica-Kucukoglu GE.(1997): Vasculitis in Behcet's disease. Int Rev Immunol ., 14:81-8.

23. Sarica-Kucukoglu R, Akdag-Kose A, KayabalI M, et al. (2006): Vascular involvement in Behcet's disease: a retrospective analysis of 2319 cases. Int $\mathbf{J}$ Dermatol., 45 (8):919-21.

24. Tokay S, Direskeneli H, Yurdakul S, Akoglu T. (2001) Anticardiolipin antibo- dies in Behçet's disease: a reassessment. Rheumatology., 40: 192-195.

25. Yazc H, Chamberlain MA, Tüzün Y, et al.( 1984): A comparative study of the pathergy reaction among Turkish and British patients with Behçet's disease. Ann Rheum Dis., 43:74-5.

26. Yazc H, Yurdakul S, Hamuryudan V.(1999): Behçet's syndrome. Curr Opin Rheumatol., 11:53-7.

27. Yurdakul S, Tuzuner N, Yurdakul I, Hamuryudan V, Yaz1c1 H. (1996) Gastrointestinal involvement in Behçet's syndrome: a controlled study. Ann Rheum Dis., 55:208-10.

28. Zouboulis CC, Buttner $\mathbf{P}$, Tebbe B, Orfanos CE. (1993): Anticardiolipin antibodies in Adamantiades-Behçet's disease. Br J Dermatol.,128:281-4. 


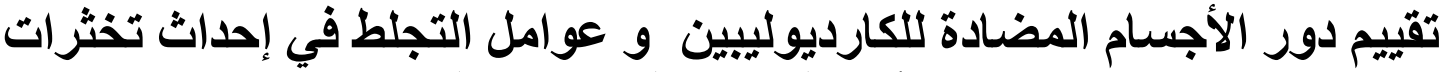 و جلطات الام في الأوعية الاموية المصاحبة لمرض عرض بهنت}

\section{سهام محمد سعيد النقيب* أحمد محمد راغب *** هشام سعد الباز*** عبد الشافي

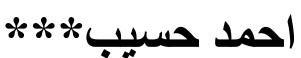

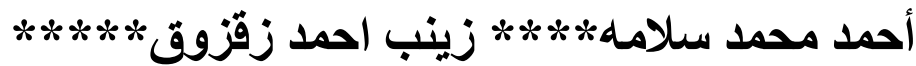

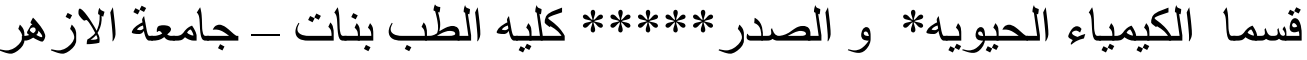

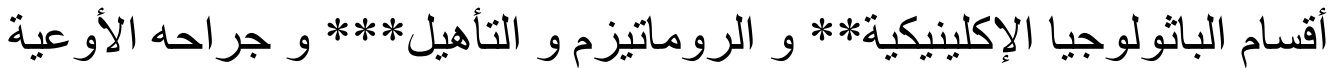

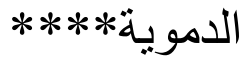

كليه الطب - جامعة الأزهر

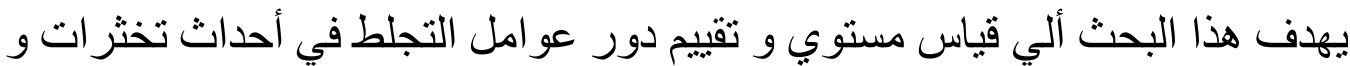

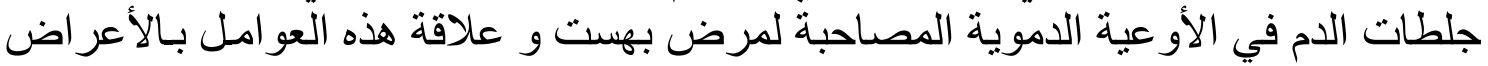

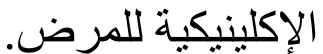

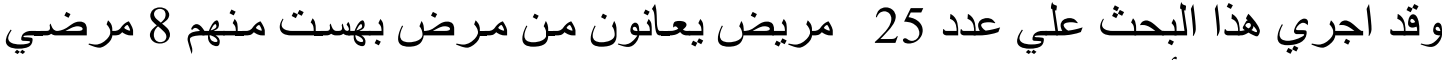

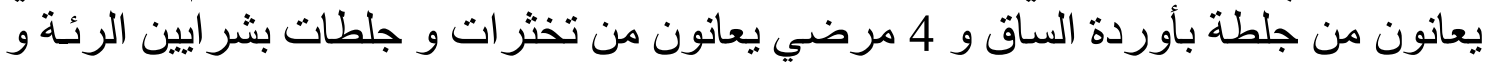

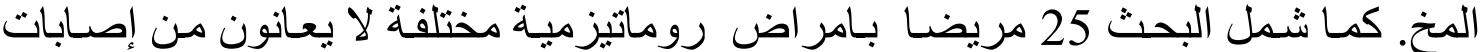

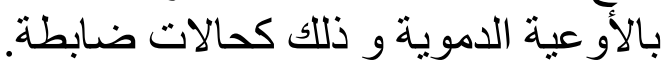

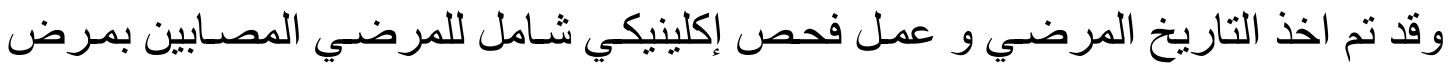

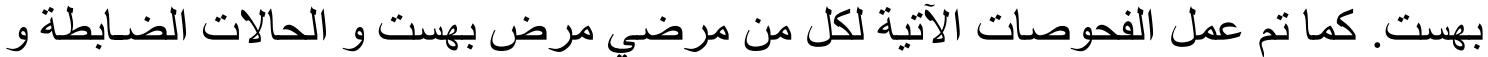

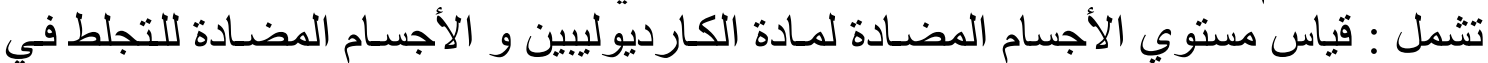

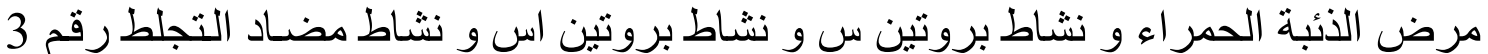

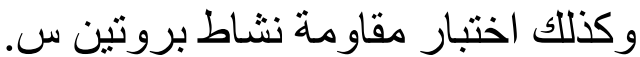

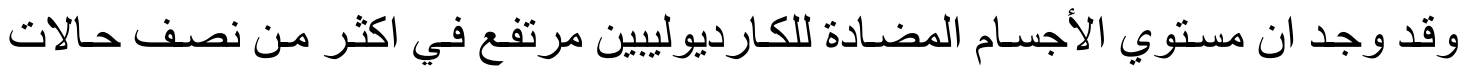

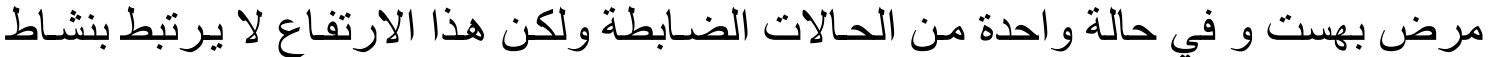

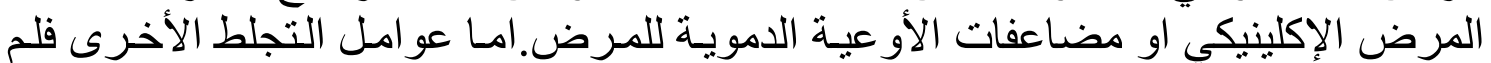

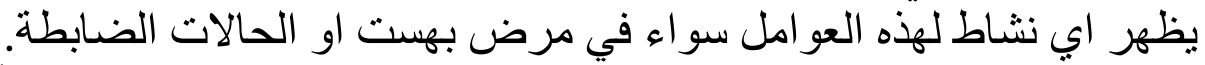

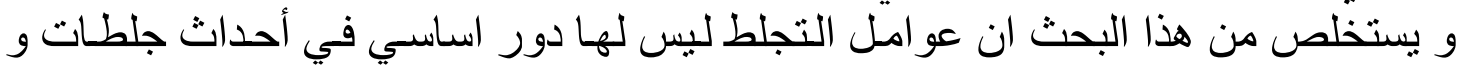

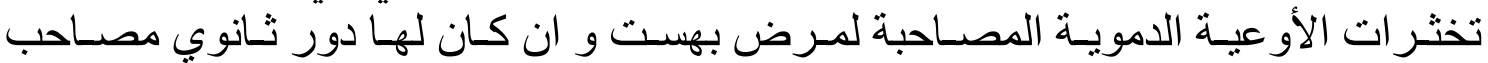
ل التهابات الأو عية الدموية. 